\title{
Compliance with iron folic acid and associated factors among pregnant women through pill count in Hawassa city, South Ethiopia: a community based cross- sectional study
}

Zemenu Yohannes Kassa*, Tegibelu Awraris, Alemneh Kabeta Daba and Zelalem Tenaw

\begin{abstract}
Background: Iron deficiency anemia during pregnancy is a public health problem across the globe that adversely affects maternal and perinatal outcome. World Health Organization recommends that universal iron folic acid supplementation of pregnant women. Therefore, the aim of this study was to determine compliance and identify factors associated with Iron folic acid among pregnant women.

Methods: Community based cross-sectional study was conducted from November 01-December 30, 2015 on pregnant women from Hawassa city. An Interviewer administered questionnaire was used to collect data from 422 selected study subjects using simple random sampling technique. Data were entered in to Epi-Data version 3.1 and exported to SPSS version 20 for analysis. Bivariate and multivariable analyses were employed to test presence of association between dependent and independent variables. $P$ value $<0.05$ was considered as statistically significant.

Result: In this study prevalence of compliance with iron folic acid was reported 38.3\% (95\%Cl: 33.1, 42.5). Women who know the importance of iron folic acid had 6 times higher odds of compliance with iron folic acid than counterpart ( $A O R=6.1,95 \% \mathrm{Cl}: 3.53,10.24)$. Pregnant women who develop complication during the previous pregnancy had 0.34 times lower odds of compliance with counterpart (AOR $=0.34,95 \% \mathrm{Cl}$ : 0.16-0.76), experiencing iron folic acid related side effects during the previous pregnancy had 8.5 time higher odds to decrease compliance with than those did not experience iron folic acid related side effects ( $A O R=8.5,95 \% \mathrm{Cl}$ : 4.65.-15.35).

Conclusion: In this study demonstrated that compliance with iron folic acid among pregnant women through pill count is low. Women who know the importance of iron folic acid, women who develop complications during previous pregnancy, experiencing iron folic acid related side effects during the previous pregnancy were independent predictor of compliance with iron folic acid. Health care providers shall strongly counsel the importance and side effect of iron folic acid before prescribing. The responsible bodies avail suitable iron folic acid pill and less side effect brands. Health care providers and health extension workers shall be monitored iron folic acid by pill count during their home to home visits.
\end{abstract}

Keywords: Iron folic acid Compliance, Pill count, Ethiopia

* Correspondence: zemenu2013@gmail.com

College of Medicine and Health Sciences, Hawassa University, Hawassa,

Ethiopia

(c) The Author(s). 2019 Open Access This article is distributed under the terms of the Creative Commons Attribution 4.0 International License (http://creativecommons.org/licenses/by/4.0/), which permits unrestricted use, distribution, and reproduction in any medium, provided you give appropriate credit to the original author(s) and the source, provide a link to the Creative Commons license, and indicate if changes were made. The Creative Commons Public Domain Dedication waiver (http://creativecommons.org/publicdomain/zero/1.0/) applies to the data made available in this article, unless otherwise stated. 


\section{Plain English summary}

Compliance with iron folic acid is a key means to prevent and control of physiological anemia during pregnancy. Iron folic acid compliance is stated that the woman take four tablet atleast per week ( $\geq 4$ times per week) or for $\geq 90$ days at third trimester of pregnancy.

In this study the participants were asked through close ended and pretested structured questionnaire face to face interviews whether or not they took iron folic acid $\geq 4$ times per week through pills count. Of the total 422, 383(95.3\%) were married. The findings showed that $38.3 \%$ pregnant compliance with iron folic acid through pills count.

The possible determinants were: had complications at previous pregnancy, experienced of side effects at previous pregnancy and being informed of IFA's importance.

In conclusion: compliance with iron folic acid during pregnancy is low in Hawassa city. This findings recommend that there is a need to give attention the way of iron folic acid taking during pregnancy.

\section{Background}

Anemia remains a public health problem across the globe. It affected more than 2 billion people globally, accounting for 60,534 deaths in 2010 for reproductive age women. Pregnant women are predominantly at high risk of iron deficiency anemia (IDA) due to increase nutrient requirement during pregnancy $[1,2]$.

Globally, almost $47.4 \%$ preschool children, $41.8 \%$ pregnant women and $30.2 \%$ non-pregnant women were anemic $[1,3]$. The prevalence of clinical anemia, anemia, ID (iron deficiency) and IDA in Ethiopia were 11.3, 30.4, 49.7 and $17.0 \%$ respectively [4].

Iron deficiency anemia contributes adversely pregnancy outcomes. Iron deficiency anemia during pregnancy is associated with an increased risk factor for maternal low weight gain, preterm labour, placenta previa, premature rupture of membrane, cardiac arrest, and hemorrhage, lowered resistance to infection, poor cognitive development and reduced work capacity. Similarly iron deficiency anemia on fetal and neonatal are increasing risk factor of prematurity, low birth weight, fetal distress which contribute to perinatal morbidity and mortality $[5,6]$.

Folic acid deficiency at conception is associated with risk factor of neural tube defects and other adverse pregnancy outcomes such as preeclampsia, malformations like facial clefts, spontaneous abortion, fetal death, fetal growth restriction, and preterm delivery. IFA supplementation and food fortification are now feasible strategy recommended to prevent such adverse pregnancy outcomes [7, 8].

WHO's recommendation of IFA supplementation to pregnant women consider the existing magnitude of anemia: women live in area with $40 \%$ anemia to take $60 \mathrm{mg}$ iron plus $400 \mu \mathrm{g}$ folic acid on daily basis, in area with $20 \%$ anemia intermittent oral iron $120 \mathrm{mg}+2800 \mu \mathrm{g}$ folic acid once weekly $[9,10]$.

A Study suggest that compliance with IFA is the major way of prevention and control of anemia and neural tube defect [11].

According to WHO's compliance with IFA cut off pregnant woman is expected to take $\geq 90$ IFA tablets on daily basis [12]. Studies conducted in India, Nigeria, and Sudan revealed that overall compliance with IFA tablets among pregnant women were $64.7,65.9$ and $91.1 \%$ respectively $[8,13]$.

According to the 2016 Ethiopian Demographic and Health Survey (EDHS) report in southern part of the country $4.2 \%$ of pregnant women took IFA $\geq 90$ days [14]. In Ethiopia one of the strategies being implemented to prevent and control anemia and neural tube defect is universal supplementation of IFA for pregnant women. Studies done at different parts of the country revealed that 20.4\% in Amhara region, and $74.9 \%$ in Tigray region, and $37.1 \%$ in South region were pregnant women compliance with IFA [15-17].

Studies showed that side effects, forgetfulness and shortage of supplement were major reason of non-compliance with IFA $[15,16]$.

Hence, assessment of compliance and identifying of factors associated with IFA is an important step to improve IFA intake among pregnant women. Despite the last fifteen years maternal and child health problems significantly decreased by applying different programs and interventions, anemia remains a substantial health problem in resource limited countries. Conversely another study confirmed that side effects of IFA had very limited influence on compliance, while by decreasing side effects of IFA may not be a successful strategy for improving compliance with IFA [13].

In Ethiopia minister of health being implemented among the strategies to prevent and control iron deficiency anemia and neural tube defects are universal supplement of IFA for pregnant women, meanwhile anemia remains unacceptable high. In Ethiopia compliance with IFA through pill count is limited data. Therefore, the aim of this study was to determine compliance and identify factors associated with IFA among pregnant women.

\section{Methods}

\section{Study design, and study setting}

Community based cross sectional study was carried out from November 01-December 30, 2015 among pregnant women who took IFA in Hawassa city.

Hawassa is administrative city of southern nation's nationalities, people regional state (SNNPRS) and located $273 \mathrm{~km}$ south from Addis Ababa. According to the city health department estimation report in 2015/16, there were 351,567 resident in Hawassa. From the total population170, 510(48.5\%) were females. Women who were in child bearing age group (15-49) were 69, 769, from this, 
12, 167 were pregnant. The city has 8 sub-city and 32 kebeles (smallest administrative unit), which have 83 public and private health institutions. One public referral and teaching hospital, one public general hospital,4 private primary hospitals, 9 public health centers, 17 health posts and 51 private clinics.

In Ethiopia IFA supplement is fundamental component of ANC. In the public health institution IFA supplementation is free of charge which is uncoated and the brand name is fefol.

\section{Sampling}

Sample size was determined using single population proportion formula by taking the proportion of compliance with IFA through pill count $50 \%$, at $95 \%$ confidence interval $(\mathrm{CI})$ and an acceptable difference of $5 \%$. Considering $10 \%$ non-response rate, the total sample size was 422 .

There are 32 kebeles in the study area. Ten kebeles were selected using simple random sampling technique and home to home census was performed prior to one week data collection period to identify study participants in the third trimester of pregnancy who were supplemented to IFA tablets at first booking ANC for 3 months in the selected kebeles. Through census 1003 identified women who were supplemented to IFA tablets more than 3 months.

After having the list of all women in the third trimester of pregnancy who were supplemented to IFA tablets more than 3 months, with their respective houses codes were assigned for each pregnant women, and a new sampling frame was constructed. Simple random sampling technique was used. By using these numerical codes, study subjects were drawn by Open Epi, computer software.

\section{Inclusion and exclusion criteria}

All women in the third trimester of pregnancy who were supplemented to IFA tablets at first booking ANC for 3 months in the selected kebeles were included. Women in the third trimester of pregnancy who were critically ill during data collection period, psychiatric problem, and on treatment of anemia were excluded.

Operational definition, Compliance defined as the willingness and ability of pregnant women to uptake IFA supplementation on daily basis. The level of compliance was assessed the following ways: the women took atelast 51 from 90 pill or the women took $\geq 4$ times per week on daily basis (atleast 51 from 90 pill) through pill count [5].

Obstetric complication during pregnancy are vaginal bleeding, loss of consciousness, preterm labour, premature rapture of membrane and prolonged labour [18].

Side effect of iron folic acid are heart burn, nausea, vomiting, color change of stool and urine(black), constipation and intense abdominal pain [19].

\section{Data collection tool and quality control}

Data collection was carried out in the community home to home. It was collected by face to face interview technique by using pretested questionnaire and pills were counted by direct observation. Questionnaire was developed by reviewing different existing literatures. First, the questionnaire was designed at English and then translated to Amharic and back to English to check consistency. A questionnaire was consisted of sociodemographic,obstetric and compliance with IFA variables. Pretest was conducted among 21 women (5\% of the total sample size) and (Cronbach's Alpha was 0.84 ) for internal validity of the tool in Yirgalem town. Based on the feedback and findings of the pretest, necessary correction and amendment was done before starting of the actual data collection. One day training was given for data collectors and supervisors on the content of questionnaire and its administration. Data were collected by ten diploma midwives and supervised by two BSc midwives.

\section{Data processing and analysis}

Data were checked, coded and entered in to Epi-Data 3.1 and exported to SPSS Version 20.0 software. Data cleaning was performed to check accuracy and consistencies of variables. Descriptive statistics were computed to describe the study participants. Binary logistic regression model was computed to test presence of association between dependent and independent variables. To increase the power all variables with $p$ value of less than 0.25 for bivariate logistic regression analysis were candidate for multivariable logistic regression analysis, and finally, significance was considered at $p<0.05$ with $95 \% \mathrm{CI}$.

\section{Results}

Socio demographic characteristics of pregnant women A total of 422 women in the third trimester of pregnancy was included in this study. Data from twenty (4.7\%) were excluded from analysis due to incomplete.

The mean age of pregnant women were 25.7 $\pm 4.2 \mathrm{SD}$. About 383(95.3\%) of pregnant women were married, $125(31.1 \%)$ had college/university education, 162(40.3\%) were house wives and 75(18.7\%) were under poverty line (Table 1).

\section{Obstetric characteristics of pregnant women}

One hundred forty four 144(35.8\%) were gravida II (had 2nd pregnancy), and $149(37.1 \%)$ were para I (the 1st birth including still birth). More than half, 228 (56.7\%) of the pregnancy was unplanned. Women in the third trimester of pregnancy who took IFA $\geq 4$ times per week for $\geq 90$ days were 154 (38.3\%) (95\%CI: 33.1, 42.5) (Table 2). Pregnant women who watched medical advice on TV atleast once per two week 236(58.5\%) and 233(55.5\%) never read medical magazine (Table 1 ). 
Table 1 General characteristics of pregnant women in Hawassa city, South Ethiopia, 2015

\begin{tabular}{|c|c|c|c|}
\hline Variable & & $\begin{array}{l}\text { Number } \\
(N=402)\end{array}$ & Percent (\%) \\
\hline \multirow[t]{4}{*}{ Age } & $<18$ & 3 & 0.7 \\
\hline & $18-25$ & 184 & 45.8 \\
\hline & $26-35$ & 211 & 52.5 \\
\hline & $>35$ & 4 & 1 \\
\hline \multirow[t]{3}{*}{ Marital status } & Windowed & 4 & 1 \\
\hline & Single & 15 & 3.7 \\
\hline & Married & 383 & 95.3 \\
\hline \multirow[t]{5}{*}{ Religion } & Others@ & 4 & 1 \\
\hline & Catholic & 11 & 2.7 \\
\hline & Muslim & 37 & 9.2 \\
\hline & Orthodox & 168 & 41.8 \\
\hline & Protestant & 182 & 45.3 \\
\hline \multirow[t]{5}{*}{ Educational status } & No formal education & 39 & 9.7 \\
\hline & $1-4$ grade & 50 & 12.4 \\
\hline & $5-8$ grade & 109 & 27.1 \\
\hline & 9-12 grade & 79 & 19.7 \\
\hline & $\begin{array}{l}\text { College/university } \\
\text { education }\end{array}$ & 125 & 31.1 \\
\hline \multirow[t]{5}{*}{ Occupation } & NGO employee & 6 & 1.5 \\
\hline & Merchant & 61 & 15.2 \\
\hline & Daily labor & 67 & 16.7 \\
\hline & Government employee & 106 & 26.4 \\
\hline & House wife & 162 & 40.3 \\
\hline \multirow[t]{3}{*}{ Monthly income ${ }^{a}$} & Don't know & 26 & 6.5 \\
\hline & $\begin{array}{l}<1313 \text { Eth birr } \\
(<59.7 \text { USD })\end{array}$ & 75 & 18.7 \\
\hline & $\begin{array}{l}\text { 1313.5-9900Eth birr } \\
\text { (59.7-450 USD) }\end{array}$ & 301 & 74.9 \\
\hline \multirow[t]{5}{*}{ Husband education } & No formal education & 3 & 0.7 \\
\hline & $1-4$ grade & 21 & 5.2 \\
\hline & $5-8$ grade & 57 & 14.2 \\
\hline & 9-12 grade & 101 & 25.1 \\
\hline & College/University education & 220 & 54.7 \\
\hline \multirow[t]{3}{*}{ Family size } & $>6$ & 21 & 5.2 \\
\hline & $4-6$ & 217 & 54 \\
\hline & $<4$ & 164 & 40.8 \\
\hline \multirow{3}{*}{$\begin{array}{l}\text { Frequency of on } \\
\text { TV medical advice } \\
\text { follow-up }\end{array}$} & Once a week & 72 & 17.9 \\
\hline & Once every two weeks & 236 & 58.7 \\
\hline & Never & 94 & 23.4 \\
\hline \multirow{3}{*}{$\begin{array}{l}\text { Frequency of reading } \\
\text { medical magazine }\end{array}$} & Once a week & 88 & 21.9 \\
\hline & Once every two weeks & 91 & 22.6 \\
\hline & Never & 233 & 55.5 \\
\hline
\end{tabular}

a 1 USD was 22 Ethiopian birr, others@ like Seventh Day Adventist, Jehovah Witness

Income under extreme poverty $<1.25$ USD per day

Under poverty1.25-2USD per day

Above poverty line $>$ 2USD per day
Table 2 Obstetrical characteristics of pregnant women in Hawassa city, South Ethiopia, 2015

\begin{tabular}{|c|c|c|c|}
\hline Variable & & $\begin{array}{l}\text { Number } \\
(N=402)\end{array}$ & Percent (\%) \\
\hline \multirow[t]{4}{*}{ Number of pregnancy } & 1 & 142 & 35.3 \\
\hline & 2 & 144 & 35.8 \\
\hline & $3-4$ & 99 & 24.6 \\
\hline & $>4$ & 17 & 4.2 \\
\hline \multirow[t]{4}{*}{ Number of live birth } & Nulipara & 114 & 28.4 \\
\hline & Para I & 149 & 37.1 \\
\hline & Para I-III & 124 & 30.8 \\
\hline & Para IV and above & 15 & 3.7 \\
\hline \multirow[t]{5}{*}{ Number of ANC contact } & One times & 43 & 10.7 \\
\hline & Two times & 90 & 22.4 \\
\hline & Three times & 129 & 32.1 \\
\hline & Four times & 101 & 25.1 \\
\hline & Five and above times & 39 & 9.7 \\
\hline \multirow[t]{2}{*}{ Is pregnancy planned? } & yes & 174 & 43.3 \\
\hline & no & 228 & 56.7 \\
\hline \multirow[t]{2}{*}{$\begin{array}{l}\text { How many tablets } \\
\text { took per day the } \\
\text { last } \geq 90 \text { days }\end{array}$} & $\begin{array}{l}\text { Iron folic acid was } \\
\text { taken } \geq 4 \text { time per } \\
\text { week ( } 51 \text { from } 90 \text { pill) }\end{array}$ & 154 & 38.3 \\
\hline & $<4$ times per week & 248 & 61.7 \\
\hline
\end{tabular}

\section{Pregnant women reason of taking IFA}

Among 402 IFA supplement study participant reported that $345(85.8 \%)$ took for the prevention anemia (Table 3). Near to one-third of the study participants, 121(30.1\%) were feared to fetal size increment was the main mentioned reason of non-compliance with IFA (Fig. 1).

Table 3 Pregnant women reason IFA taking in Hawassa city, South Ethiopia, 2015

\begin{tabular}{llll}
\hline Variable & Number & Percent (\%) \\
& $(N=402)$ & \\
\hline Develop complications during the & Yes & 110 & 27.4 \\
previous pregnancy & No & 292 & 72.6 \\
Women who know how to take IFA & Yes & 213 & 53 \\
& No & 189 & 47 \\
Taking IFA for prevention of anemia & Yes & 345 & 85.8 \\
& No & 57 & 14.2 \\
Had anemia during the previous pregnancy & Yes & 203 & 50.5 \\
& No & 199 & 49.5 \\
Discussion the importance of IFA with & Yes & 338 & 84.1 \\
your friends & No & 64 & 15.9 \\
Women who know I the importance of IFA & Yes & 199 & 49.5 \\
& No & 203 & 50.5 \\
Taking IFA for prevention of NTD & Yes & 211 & 52.5 \\
\hline & No & 248 & 61.7 \\
\hline
\end{tabular}



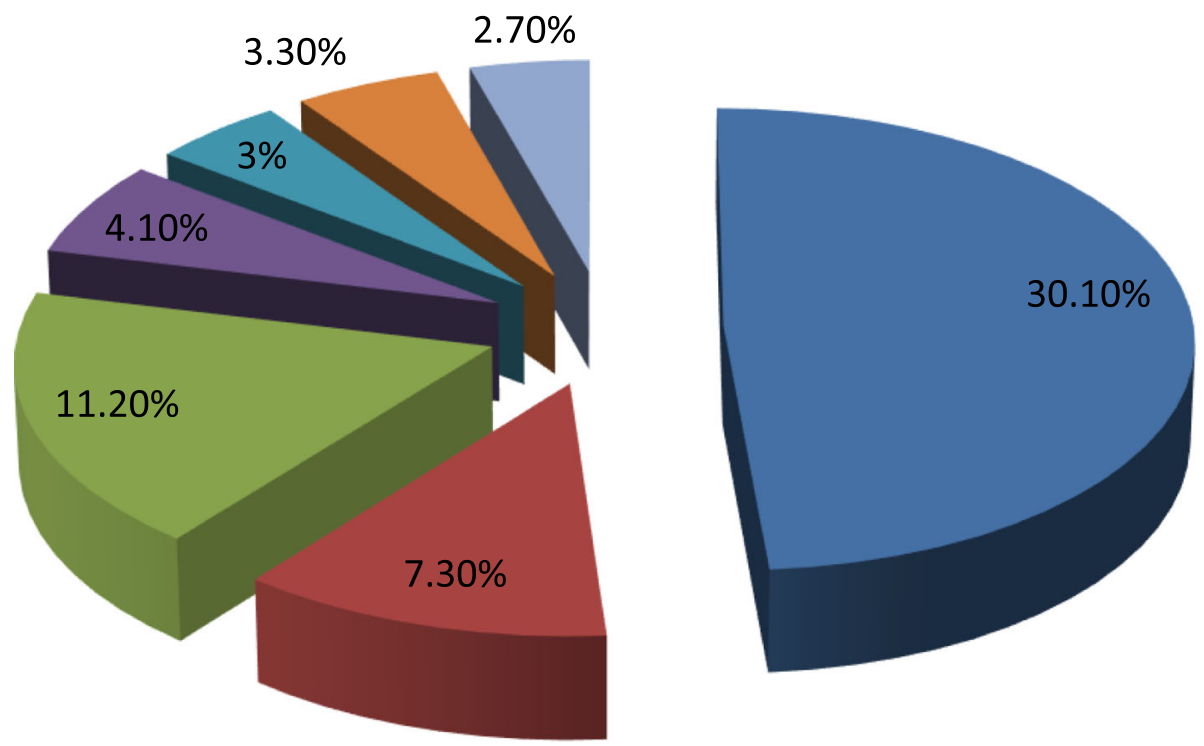

fear of increase fetus size

nausea

hear burn

forgetfullness

vomiting

fear of side effect

stool color change

Fig. 1 Pregnant women's the reason of non-compliance of iron folic acid taking in Hawassa city, South Ethiopia, 2015

\section{Factors associated compliance with IFA among pregnant} women

Women who know the importance of iron folic acid had 6 time higher odds of compliance with iron folic acid than counterpart $(\mathrm{AOR}=6.1,95 \% \mathrm{CI}$ : 3.53, 10.24). Pregnant women who develop complication during the previous pregnancy had 0.34 times lower odds of compliance with counterpart $(\mathrm{AOR}=0.34$, 95\% CI: 0.16-0.76), experiencing iron folic acid related side effects during the previous pregnancy had 8.5 times higher odds to decrease compliance with IFA than those who did not experience iron folic acid related side effects $(\mathrm{AOR}=8.5,95 \% \mathrm{CI}$ : 4.65.-15.35) (Table 4).

\section{Discussion}

Compliance with IFA is a key strategy of prevention and control of iron deficiency anemia and neural tube defect for pregnant women and unborn child. Nevertheless, it is low in developing countries, including Ethiopia. This study determined the prevalence of compliance with IFA among pregnant women through pill count by direct observation of the pill. It is cost effective and applicable in low and middle income countries to assess compliance. This study showed that compliance with IFA through pills count at third trimester of pregnancy was reported $38.3 \%$.This finding is higher than the study done in Amhara region and compliance with IFA supplementation self-reporting was reported 20.4\% [20]. A possible 
Table 4 Factors associated compliance with IFA among pregnant women in Hawassa city, South, Ethiopia, 2015(N = 402)

\begin{tabular}{|c|c|c|c|c|}
\hline Variable & Compliance $(N=154)$ & Non-compliance $(N=248)$ & COR 95\% Cl & AOR 95\% Cl \\
\hline \multicolumn{5}{|c|}{ Discussion the importance of IFA with your friends } \\
\hline Yes & 123 & 215 & $1.642(0.959,2.812)$ & $1.55(0.74,3.23)$ \\
\hline No & 31 & 33 & 1 & \\
\hline \multicolumn{5}{|c|}{ Fearing to take IFA for fetal size increment } \\
\hline Yes & 30 & 73 & $0.58(0.358 .0 .94) *$ & $1.29(0.58,2.87)$ \\
\hline No & 124 & 175 & 1 & \\
\hline \multicolumn{5}{|c|}{ Develop complications during the previous pregnancy } \\
\hline Yes & 25 & 85 & $0.37(0.225,0.614)^{*}$ & $0.34(0.16,0.76) *$ \\
\hline No & 129 & 163 & 1 & \\
\hline \multicolumn{5}{|c|}{ Is pregnancy planned } \\
\hline Yes & 53 & 121 & $0.551(0.364,0.834)^{*}$ & $1.13(0.67,1.91)$ \\
\hline No & 101 & 127 & 1 & \\
\hline \multicolumn{5}{|c|}{ Experiencing IFA related side effects during the previous pregnancy } \\
\hline Yes & 122 & 84 & $7.44(4.65,11.91) *$ & $8.5(4.65,15.35)^{*}$ \\
\hline No & 32 & 164 & 1 & \\
\hline \multicolumn{5}{|c|}{ Taking IFA for prevention of anemia } \\
\hline Yes & 32 & 25 & $2.34(1.33,4.13) *$ & $1.31(0.56,2.91)$ \\
\hline No & 122 & 223 & 1 & \\
\hline \multicolumn{5}{|c|}{ Had anemia at the previous pregnancy } \\
\hline Yes & 87 & 112 & & \\
\hline No & 67 & 136 & $1.58(1.05,2.36) *$ & $0.68(0.15,3.19)$ \\
\hline \multicolumn{5}{|c|}{ Women who know the importance of IFA } \\
\hline Yes & 120 & 83 & $7.02(4.42,11.15) *$ & $6.1(3.53,10.24) *$ \\
\hline No & 34 & 165 & 1 & \\
\hline \multicolumn{5}{|c|}{ Women who know how to take IFA } \\
\hline Yes & 71 & 142 & $0.64(0.43,0.96) *$ & $0.47(0.28,82)$ \\
\hline No & 83 & 106 & 1 & \\
\hline
\end{tabular}

explanation for this higher compliance is might be due to the above study takes place within 12 month after the women gave birth and it is self-reporting of IFA intake while in this study during the pregnancy and pill count by observation. Another possible explanation could be due to study setting could contribute to the findings difference. Thus, this study participant's access to IFA benefits related health information could be better than the previous study.

This finding is in agreement with the study done in Mangalore, India was 37.1\% [21]. (The possible explanation might be happen as acknowledge of the mother related to the use of IFA during pregnancy which enhanced to take IFA properly.

Even though, this finding is inconsistent with the study done in Mangalore India, Mozambique,Vietnam and Madhya Pradesh India 64.7,79,85 and 89\% respectively [21-24]. This difference could be explained by sociocultural differences of study groups, study setting and the way of assessing compliance with IFA in different ways. Another possible explanation could be in Ethiopia at public health institution during ANC universally uncoated IFA pill is freely given for pregnant women. This study is in line with the study done in Philippines and Egypt 40.3 and $41.1 \%$ respectively through pill count $[25,26]$. The possible explanation might be due to the way of defining compliance with IFA through pill count. But lower than the study done in Senegal 69\% through pill count [27].

A possible explanation for this lower compliance with IFA might be due to socioeconomic differences of the study groups, time, study setting and population and the previous study assessed compliance with IFA at 20 wk., but this study assessed compliance at third trimester of pregnancy.

This finding is coincided to the study done in Indonesia $36 \%$ through stool examination [28]. In this study, the reason of non-compliance is experiencing of side effect, 
forgetfulness, nausea, heartburn and fear of fetal size increment $3.3,4.1,7.3$ and $11.2 \%$ and $30.1 \%$ respectively. It is in line with different studies done [20-25, 27, 29]. A possible explanation might be due to poor counseling of the importance of IFA before prescribing it.

In this study pregnant women who develop complication during the previous pregnancy had 0.34 times lower odds of compliance with counterpart (AOR $=0.34,95 \%$ CI: $0.16-0.76)$. This finding is coincided to $(\mathrm{AOR}=1.52$, 95\% CI: 1.31-1.75) [30].

In this study experiencing iron folic acid related side effects during the previous pregnancy had 8.5 times higher odds to decrease compliance with IFA than those who did not experience iron folic acid related side effects $(\mathrm{AOR}=8.5,95 \% \mathrm{CI}$ : 4.65.-15.35), this finding is in line with the study done in Egypt [26, 31]. In this study Women who know the importance of iron folic acid had 6 time of higher odds of compliance with iron folic acid than counterpart $(\mathrm{AOR}=6.1,95 \% \mathrm{CI}: 3.53,10.24)$. This finding is in inconsistent to $\mathrm{WHO}$ report $\mathrm{AOR}=0.05$, 95\% CI: 0.04,0.07) [29]. This might be happened due to study setting, time, population and the way of addressing compliance with IFA.

The possible strength of this study is used pill count by direct observation. To assess compliance with IFA through pill count by direct observation is cheap and cost effective compared electronics pill count and stool examination. It is applicable in low and middle income countries. The possible limitations of this study did not include that gold standard methods of measuring number of IFA uptake electronics pill count method and stool examination or biochemical methods to measure level of compliance with IFA. Compliance with IFA is one of the strategies to prevent and control iron deficiency anemia and neural tube defect for pregnant women and unborn child [32].

\section{Conclusion and recommendation}

In this study demonstrated that compliance with IFA among pregnant women through pill count is low. Women who know the importance of iron folic acid, women who develop complications during previous pregnancy, experiencing iron folic acid related side effects during the previous pregnancy were independent predictor of compliance with iron folic acid. Health care providers shall strongly counsel the importance and side effect of iron folic acid before prescribing. The responsible bodies avail suitable iron folic acid pill and less side effect brands. Health care providers and health extension workers shall be monitored iron folic acid by pill (tablet) count during their home to home visits.

\section{Abbreviations}

ANC: Antenatal Care; AOR: Adjusted odds ratio; Cl: Confidence Interval; EDHS: Ethiopian Demographic and Health Survey; ID: Iron deficiency;
IDA: Iron deficiency anemia; NTD: Neural Tube Defect; SD: Standard deviation; SNNPRS: Southern Nations, Nationalities and People Regional State; WHO: World health organization

\section{Acknowledgements}

The authors' would like to acknowledge College of Medicine and Health Sciences Hawassa University for covering the data collection cost. The authors' would like to say thank you to the data collectors and study participants

\section{Funding}

Hawassa university funded seed money to cover data collection cost.

Availability of data and materials

We send all data which is available us, there is not remaining data and materials.

Authors' contributions

ZYK, TA, AKD and ZT: designed research, conducted research, wrote paper, analyzed data and edited paper. All authors read and approved the final manuscript.

\section{Author's information}

Zemenu Yohannes: MSc in Maternity and Reproductive Health Nursing, School of Nursing and Midwifery, College of Medicine and Health Sciences, Hawassa University, Hawassa, Ethiopia.

Tegibelu Awraris: MSc in Epidemiology School of Public Health and Environmental Health, College of Medicine and Health Sciences, Hawassa University, Hawassa, Ethiopia.

Alemneh Kabeta: MSc in Applied Human Nutrition, School of Nursing and Midwifery, College of Medicine and Health Sciences, Hawassa University, Hawassa, Ethiopia.

Zelalem Tenaw: MSc in Maternity and Reproductive Health Nursing, School of Nursing and Midwifery, College of Medicine and Health Sciences, Hawassa University, Hawassa, Ethiopia.

\section{Ethics approval and consent to participate}

Ethical clearance was obtained from Institution Review Board (IRB) of College of Medicine and Health Sciences (Ref No IRB/049/08).

Ethical clearance paper was presented to Hawassa city administration health office to get permission letter to undertake research activities in selected kebeles and verbal consent also took from the participants. Participation was based on willingness after information sheet was explained the study participant. There was no harm with participation in this interview and to show IFA (tablets) pill. Participants were told as they have full right to stop interview any time if they did not want to participate. Confidentiality was assured making the questionnaire anonymous.

Consent for publication

Not applicable.

\section{Competing interests}

The authors declare that they have no competing interests.

\section{Publisher's Note}

Springer Nature remains neutral with regard to jurisdictional claims in published maps and institutional affiliations.

Received: 5 November 2018 Accepted: 24 January 2019

Published online: 08 February 2019

\section{References}

1. De Benoist B, McLean E, Egli I, editors. CM. World wide prevalence of anemia 1993-2005: WHO global database on anemia. Geneva: WHO, CDC; 2008.

2. Rahman MM, Abe SK, Rahman MS, Kanda M, Narita S, Bilano V, et al. Maternal anemia and risk of adverse birth and health outcomes in low-and middle-income countries: systematic review and meta-analysis. Am J Clin Nutr. 2016;103(2):495-504.

3. Badham J, Zimmermann MB, editors. KK. The guide book nutritional anemia. Basel: Sight and Life; 2007. 
4. Melaku $U$, et al. Iron deficiency anaemia among women of reproductive age in nine administrative regions of Ethiopia. Ethiop J Heal Dev. 2006;22.3: 252-8.

5. ZAKIA M, Ibrahim MD, Seham Abd El-Hamid MDH, Mikhail MS, et al. Assessment of adherence to Iron and folic acid supplementation and prevalence of Anemia in pregnant women Ismailia governorate, Egypt. Med J. 2011;79(2):115-21

6. Begum S. Factors associated with adherence to Iron Folic acid supplementations during Pregnancy in Uttar Pradesh. 2012;12(2).

7. Sengpiel V, et al. Retracted: Folic acid supplementation, dietary folate intake during pregnancy and risk for spontaneous preterm delivery: a prospective observational cohort study. BMC Pregnancy Childbirth. 2013;13.1.

8. Ogundipe O, Hoyo C, Stbye T, Oneko O, Manongi R, Terje R, et al. Factors associated with prenatal folic acid and iron supplementation among 21,889 pregnant women in urban areas Tanzania: a cross-sectional hospital based study. BMC Public Health Nutrition. 2012;12:481.

9. WHO. Guideline: Daily iron and folic acid supplementation in pregnant women. Geneva: WHO; 2006.

10. Organization WH. Guideline: daily iron and folic acid supplementation in pregnant women. 2012. Geneva, Switzerland: World Health Organization; 2014.

11. United Nations High Commissioner for Refugees. Handbook for Emergencies. Geneva2007.

12. Organization $\mathbf{W H}$. Developing and validating an iron and folic acid supplementation indicator for tracking progress towards global nutrition monitoring framework targets: final report June 2018. 2018.

13. Mithra P, Unnikrishnan B, Rekha T, Nithin K, Mohan K, Kulkarni V, et al. Compliance with iron-folic acid (IFA) therapy among pregnant women in an urban area of South India. Afr Health Sci. 2013;13(4):800-85.

14. Chakma T, Rao PV, Meshram PK. Factors associated with high compliance/ feasibility during iron and folic acid supplementation in a tribal area of Madhya Pradesh, India. Public Health Nutr. 2013;16(02):377-80.

15. Gebre A, Mulugeta A, Etana B. Assessment of factors associated with adherence to Iron-folic acid supplementation among urban and rural pregnant women in North Western zone of Tigray, Ethiopia: comparative study. International journal of nutrition and food. Sciences. 2014:4(2):161-8.

16. Gebremedhin S, et al. Coverage, compliance and factors associated with utilization of iron supplementation during pregnancy in eight rural districts of Ethiopia: a cross-sectional study. BMC Public Health. 2014;14:607.

17. Taye B. Factors associated with compliance of prenatal iron folate supplementation among women in Mecha district, Western Amhara: a cross-sectional study. Pan Afr Med J. 2015;20(43)

18. Amenu G, Mulaw Z, Seyoum T, Bayu H. Knowledge about danger signs of obstetric complications and associated factors among postnatal mothers of Mechekel District health centers, east Gojjam zone, Northwest Ethiopia, 2014. Scientifica. 2016;2016.

19. Hyder SZ, Persson LÅ, Chowdhury A, Ekström E-C. Do side-effects reduce compliance to iron supplementation? A study of daily-and weekly-dose regimens in pregnancy. J Health Popul Nutr. 2002:175-9.

20. Taye B, Abeje G, Mekonen A. Factors associated with compliance of prenatal iron folate supplementation among women in Mecha district, Western Amhara: a cross-sectional study. Pan Afr Med J. 2015;20(1).

21. Chakma T, Rao PV, Meshram PK. Factors associated with high compliance/ feasibility during iron and folic acid supplementation in a tribal area of Madhya Pradesh, India. Public Health Nutr. 2013;16(02):377-80.

22. Nwaru Bl, Salomé G, Abacassamo F, Augusto O, Cliff J, Sousa C, et al. Adherence in a pragmatic randomized controlled trial on prophylactic iron supplementation during pregnancy in Maputo, Mozambique. Public Health Nutr. 2015;18(06):1127-34.

23. Phuc TQ, Mihrshahi S, Casey GJ, Phu LB, Tien NT, Caruana SR, et al. Lessons learned from implementation of a demonstration program to reduce the burden of anemia and hookworm in women in Yen Bai Province. Viet Nam BMC Public Health. 2009;9(1):266.

24. Chakma T, Rao PV, Meshram PK. Factors associated with high compliance/ feasibility during iron and folic acid supplementation in a tribal area of Madhya Pradesh, India. Public Health Nutr. 2013;16(02):377-80.

25. Lutsey PL, Dawe D, Villate E, Valencia S, Lopez O. Iron supplementation compliance among pregnant women in Bicol, Philippines. Public Health Nutr. 2008;11(01):76-82.
26. Ibrahim Z, El-Hamid S, Mikhail H, Ms K. Assessment of adherence to Iron and folic acid supplementation and prevalence of Anemia in pregnant women. Med J Cairo Univ. 2011;79(2)

27. Seck BC, Jackson RT. Determinants of compliance with iron supplementation among pregnant women in Senegal. Public Health Nutr. 2008;11(06):596-605.

28. Schultink W, van der Ree M, Matulessi P, Gross R. Low compliance with an iron-supplementation program: a study among pregnant women in Jakarta, Indonesia. Am J Clin Nutr. 1993;57(2):135-9.

29. Gebremedhin S, Samuel A, Mamo G, Moges T, Assefa T. Coverage, compliance and factors associated with utilization of iron supplementation during pregnancy in eight rural districts of Ethiopia: a cross-sectional study. BMC Public Health. 2014;14(1):607.

30. Titaley CR, Dibley MJ. Factors associated with not using antenatal iron/folic acid supplements in Indonesia: the 2002/2003 and 2007 Indonesia demographic and health survey. Asia Pac J Clin Nutr. 2015;24(1):162-76.

31. Aikawa R, Jimba M, Nguen KC, Zhao Y, Binns CW, Lee MK. Why do adult women in Vietnam take iron tablets? BMC Public Health. 2006;6(1):144.

32. Organization WH. Standards for maternal and neonatal care. 2007.
Ready to submit your research? Choose BMC and benefit from:

- fast, convenient online submission

- thorough peer review by experienced researchers in your field

- rapid publication on acceptance

- support for research data, including large and complex data types

- gold Open Access which fosters wider collaboration and increased citations

- maximum visibility for your research: over $100 \mathrm{M}$ website views per year

At BMC, research is always in progress.

Learn more biomedcentral.com/submissions 